\section{Reaparece el paludismo en la Amazonia peruana}

Hasta el decenio de 1990, el número más alto de casos de paludismo (95000) registrados en el Perú se remontaba a 1944. En 1965 se había logrado el más bajo (1500) después de una intensa campaña para erradicar la enfermedad. Así, las infecciones por Plasmodium falciparum quedaron limitadas a las zonas costeras del noroeste que lindan con el Ecuador, si bien esporádicamente se informaba de casos en las zonas norte y oriente del departamento de Loreto vecinas al Brasil, Colombia y Ecuador. Sin embargo, a principios de los años noventa empezaron a observarse casos nuevos de paludismo por $P$. falciparum al norte del río Pastaza y en los límites orientales de Loreto, zonas ubicadas en la Amazonia peruana. El número incrementó rápidamente, de 140 casos en 1991 a 54290 casos confirmados por laboratorio en 1997. En ese año el paludismo en Loreto dejó un saldo de 85 muertes y 121268 casos, cifra que encierra un aumento inusitado de la enfermedad por $P$. vivax. $P$. malariae también ocasionó 44 casos en 1997. Además, recibieron tratamiento 36268 personas que se sospechaba tuvieran paludismo pero cuyo diagnóstico no pudo confirmarse, lo que elevó el total a 158115.

Durante esta epidemia se han registrado más casos en hombres $(60,5 \%)$ que en mujeres $(39,5 \%)$, probablemente debido al mayor riesgo ocupacional de exposición a los mosquitos vectores. La incidencia ha tenido una fluctuación estacional y llega a su máximo durante las lluvias de noviembre a junio. La mayor parte de los casos provienen de Iquitos que, con 345000 habitantes, es el único centro urbano de gran tamaño en Loreto. Alrededor de esa ciudad se reparte, entre pueblos y aldeas, una población rural de 474000 . La economía local se basa en la agricultura, la pesca y actividades comerciales, madereras y petroleras.

En el período de 5 años mencionado, el número de casos de paludismo en el Perú se cuadruplicó, pero en Loreto se multiplicó por 50. La infección por $P$. falciparum se ha incrementado a un ritmo mucho mayor que la ocasionada por otros plasmodios y Anopheles darlingi, vector principal de P. falciparum en la zona amazónica, se ha vuelto mucho más común. Cabe señalar que durante la epidemia descrita, el Perú registró el número de casos de paludismo más alto de toda Suramérica después del
Brasil. Uno de los problemas más acuciantes que se plantea es la evolución de cepas de $P$. falciparum resistentes a la cloroquina y a la pirimetaminasulfadoxina, lo cual requiere poner en práctica programas de tratamiento con medicamentos más eficaces. Es probable que las cepas resistentes hayan sido introducidas y diseminadas en el país por viajeros y narcotraficantes, pero la abundancia de $A$. darlingi les ha permitido prosperar de forma insólita. Durante 1996 dos estudios prospectivos de pacientes periurbanos y rurales de Loreto permitieron determinar la resistencia de $P$. falciparum a los medicamentos. Los porcentajes más altos de cepas resistentes a múltiples medicamentos se han encontrado en las zonas limítrofes de Colonia Angamos sobre el río Yavarí, las comunidades del río Blanco y en Santa Clara, cerca de Iquitos. Los parásitos evidenciaron resistencia considerable a la pirimetamina-sulfadoxina $(31 \%$ de las pruebas in vivo y $67 \%$ in vitro) y resistencia in vitro de $78 \%$ a la cloroquina. No obstante, el plasmodio se mantuvo susceptible a la mefloquina y la quinina. Se teme la posibilidad de que el paludismo se siga expandiendo a medida que $A$. darlingi prolifera y coloniza nuevos hábitat. El Programa Nacional provee a la población diagnósticos y tratamientos gratuitos y ha puesto en marcha diversas medidas de control. La población participa en la identificación y destrucción de criaderos de larvas y el uso de sustancias químicas incluye fumigación espacial y rociamientos dentro de las viviendas con piretroides y control de los criaderos de larvas con temefós. Además, se está investigando el empleo de controles biológicos como Bacillus sphaericus y B. thuringiensis. Se espera que nuevas investigaciones sobre el control ambiental, el comportamiento del vector y la resistencia del parásito a los medicamentos ayuden a establecer métodos apropiados para combatir la transmisión del paludismo en esa zona del Perú. (Aramburú Guarda J, Ramal Asayag C, Witzig R. Malaria reemergence in the Peruvian Amazon region. Emerg Infect Dis 1999;5(2):209-215.)

\section{Incidencia y tratamiento del carcinoma ductal in situ en mujeres hispanas y de otras minorías}

En los Estados Unidos de América, las tasas de incidencia del carcinoma de mama in situ en las 
mujeres se ha incrementado repentinamente en los últimos 15 años. El aumento ha sido especialmente notable con respecto al carcinoma ductal de mama in situ (CDMS), calculado en $21,4 \%$ al año entre 1982 y 1990. Las tasas de incidencia de este tipo de cáncer varían según el grupo étnico de las pacientes. De 1973 a 1992, las tasas ajustadas por edad del CDMS fueron un poco más bajas en las mujeres de etnia negra que en las de etnia blanca. Las tasas de incidencia de todos los carcinomas in situ fueron considerablemente más bajas en las mujeres de cultura hispánica $(7,8$ por 100000$)$ que en las blancas no hispánicas $(17,3$ por 100000$)$ en el período de 1988 a 1992. Hay pocos datos publicados sobre el peso de esta enfermedad en las mujeres de grupos indígenas autóctonos. El gran aumento de casos de CDMS plantea un problema de salud pública y a la vez un dilema clínico, ya que se ignora el alcance de la cirugía necesaria para erradicar el cáncer. Actualmente las opciones de tratamiento incluyen, además de la mastectomía, la cirugía conservadora de la mama con o sin radiación. Esta cirugía menos extensa parece estar teniendo resultados aceptables desde el punto de vista clínico y superiores en el sentido psicosocial.

La población multiétnica del estado de Nuevo México ofrece la oportunidad de investigar el CDMS en mujeres de estratos sociales y económicos diversos así como la forma de tratamiento que reciben en zonas rurales y urbanas. En ese estado, las tasas de incidencia muestran variaciones correspondientes a grupo étnico y además el uso de cirugía conservadora de la mama es bajo comparado con el de otras zonas del país. En un estudio reciente se investigó la información sobre incidencia del CDMS en mujeres hispanas y de origen indígena que se encuentra disponible en el Registro de Tumores de Nuevo México para el período de 1973 a 1994. También se estudiaron con datos de 1985 a 1994 las características de pacientes y médicos que pudieran estar relacionadas con el uso de cirugía conservadora. Estos factores se evaluaron por regresión logística múltiple.

Los resultados indican que en las mujeres hispanas las tasas de incidencia de CDMS fueron 50\% menores que en mujeres blancas no hispanas. La incidencia más baja se encontró en las mujeres indígenas. Se observó que desde 1985 hasta 1994 se había manifestado en las mujeres de Nuevo México un aumento anual de $21 \%$ en las tasas de incidencia de CDMS, frente a un aumento de $17 \%$ en todo el país. Entre las indígenas, las tasas de incidencia aumentaron más del doble entre 1990 y 1994. En cuanto a la cirugía conservadora de la mama, su uso aumentó 5,8\% anualmente entre 1985 y 1994 y ese fue el tratamiento recibido en 1994 por 50\% de las mu- jeres hispanas y blancas no hispanas. Su uso se diferenció por grupo de edad y fue más común en el de 70 a 79 años y menos común en el de 30 a 39 años. El lugar geográfico donde se llevó a cabo el tratamiento fue el factor más importante asociado con el empleo de ese tipo de cirugía $(P<0,001)$. Las probabilidades de recibir tratamiento conservador fueron 5,8 veces superiores en el norte del estado que en el sur. No se encontraron diferencias significativas atribuibles a etnia, residencia urbana o rural, estrato socioeconómico ni características del médico.

Debe notarse que el CDMS se diagnostica principalmente por mamografía, procedimiento cuyo empleo también aumentó durante el período estudiado. Es decir, que las tasas reducidas de incidencia de la enfermedad en hispanas e indígenas podrían reflejar un menor acceso y uso de la mamografía en estos grupos. Sin embargo, no se observó una proporción de la enfermedad correspondiente a esa hipótesis. Por lo tanto, las variaciones étnicas en las tasas pueden deberse a diferencias en factores de riesgo de carcinoma. En otros estudios se ha documentado que existe el doble de nulíparas entre las mujeres blancas no hispanas que entre las hispanas. Además, aquellas suelen tener mayor edad al primer alumbramiento. Las tasas de nacimiento en madres adolescentes son dos veces más altas entre las hispanas y las indígenas. En cuanto al tratamiento mediante cirugía conservadora tendente a conservar la mama, las variaciones mostradas probablemente reflejan diferencias en la práctica médica y en las recomendaciones según la localidad y deben conocerse los factores determinantes. (Adams-Cameron M, Gilliland FD, Hunt WC, Key CR. Trends in incidence and treatment for ductal carcinoma in situ in Hispanic, American Indian, and non-Hispanic white women in New Mexico, 1973-1994. Cancer 1999;85:1084-1090.)

\section{Uso de un sucedáneo de la sangre en casos de trauma}

Hace menos de un año que se realizó con resultados espectaculares el primer ensayo prospectivo aleatorizado del empleo, no de unidades de sangre donada, sino de una forma polimerizada de la proteína portadora de oxígeno de la hemoglobina en pacientes con lesiones traumáticas. El informe de los resultados se publicó en el número de agosto de la revista Journal of the American College of Surgeons. Los cirujanos de tres centros universitarios especializados en el cuidado de pacientes con lesiones traumáticas obtuvieron el consentimiento de 44 pacientes gravemente heridos para participar en el ensayo. 
De esa muestra se seleccionaron al azar los pacientes que recibieron el sucedáneo y los que recibieron la sangre que se les transfunde normalmente. Se consideró que el ensayo cumplía con los principios éticos de rigor por brindar una sustancia portadora de oxígeno aunque fuera diferente de la sangre.

El sucedáneo, denominado PolyHeme, es uno de nueve que se están elaborando y el único que ha progresado a los ensayos clínicos que preceden a la comercialización. Mientras que en siete de los otros sustitutos se usa la hemoglobina, el PolyHeme es el único que se basa en el proceso de polimerización. Si bien la hemoglobina es la sustancia ideal para sustituir a la sangre porque conserva oxígeno aun después de extraída de los eritrocitos, los sucedáneos que contienen hemoglobina han resultado tóxicos y han causado disfunción renal, trastornos digestivos y elevaciones súbitas de la tensión arterial así como disminuciones del ritmo cardíaco. Esa toxicidad se atribuye a la estructura de la proteína de la hemoglobina, que se compone de pequeñísimos tetrámeros moleculares. Fuera de los eritrocitos, las moléculas de hemoglobina se salen de los vasos sanguíneos y se unen al óxido nítrico, sustancia que controla la tonicidad de los vasos. Los tetrámeros impiden que el óxido nítrico relaje los vasos sanguíneos, lo que causa vasoconstricción y resulta en un aumento de la tensión arterial y en una reducción del flujo de sangre a los órganos vitales.

El PolyHeme se prepara a partir de sangre donada que ha sido cuidadosamente tamizada para que no esté contaminada con VIH ni con virus de la hepatitis. La hemoglobina se extrae y se somete a varios procesos que eliminan cualquier vestigio de virus ocultos: lavado, pasteurización y procesamiento bioquímico. En la polimerización se agruman los tetrámeros de hemoglobina para crear moléculas de mayor tamaño capaces de circular sin salirse de los vasos sanguíneos, pero no tan grandes que ocasionen problemas inmunitarios. El PolyHeme se puede administrar a cualquier persona sea cual fuere su tipo de sangre, lo que ahorra tiempo y espacio en los laboratorios. Además, puede conservarse hasta 12 meses, en contraste con las unidades de sangre donada que duran un máximo de 42 días. En el ensayo se demostró que es posible mantener la concentración total de hemoglobina reemplazando la función de los eritrocitos por la hemoglobina polimerizada. El cuerpo humano normalmente contiene 10 unidades de sangre y la cantidad administrada a los pacientes se limitó a seis unidades. No hubo ningún efecto deletéreo relacionado con el PolyHeme y se redujo casi a la mitad la cantidad de sangre donada que requerían los pacientes $(6,8$ unidades adicionales de sangre comparadas con una media de 10,4 unidades). Con todas estas ventajas, se espera que el PolyHeme revolucione el cuidado de los pacien-tes con lesiones traumáticas y salve muchas vidas. (American College of Surgeons. Blood substitute tested successfully in trauma patients. News from the American College of Surgeons, comunicado de prensa, 4 de agosto de 1998.)

\section{La conexión entre la salud bucodental y las enfermedades cardiovasculares}

En años recientes, ha aumentado rápidamente el número de informes basados en estudios epidemiológicos en los que las infecciones bucodentales se asocian con enfermedades sistémicas. El efecto de la infección microbiana de la boca en el resto del organismo no es un concepto nuevo y se remonta a los antiguos asirios antes de Cristo. La idea se ha mencionado de tiempo en tiempo, incluso a fines de los años ochenta en trabajos de investigadores finlandeses que muestran un asociación estadística entre la infección dental y la enfermedad cardiovascular. En los años noventa se ha descubierto que en las embarazadas con infecciones bucales es más alto el riesgo de tener niños prematuros de bajo peso al nacer. También se sabe desde hace años que las personas con ciertas afecciones del corazón, anormalidades de la coagulación o articulaciones artificiales son especialmente vulnerables a los microbios que viven en la cavidad bucal. Por lo común a estas personas se les recomienda tomar antibióticos antes de someterse a procedimientos dentales que puedan provocar hemorragia y una posible bacteriemia transitoria. Además se sabe que la diabetes y la enfermedad periodontal se afectan recíprocamente. Sin embargo, frente a esos datos surge un factor de confusión: las infecciones bucales son solo uno de los muchos factores importantes que pueden afectar a las enfermedades sistémicas y, en consecuencia, es difícil comprobar la relación causa y efecto.

Las infecciones bucodentales como las caries y la periodontitis son las enfermedades crónicas más comunes del mundo. Destruyen el esmalte, la dentina, las superficies de las raíces y parte del periodontio (ligamento, encía, cemento y hueso alveolar). En la cavidad bucal más de 400 especies de bacterias crean una capa que constituye un exquisito sistema ecológico y los primeros colonizadores del lugar son los estreptococos, que contribuyen a iniciar la caries dental. Actinobacillus actinomycetemcomitans, Porphyromonas gingivalis y Treponema denticola son colonizadores asociados con la periodontitis. Cuando estas bacterias se acumulan (108 o 109 unidades formadora de colonias por milígramo de placa dental) se adhieren a las superficies de los dientes y liberan continuamente elementos nocivos 
y metabolitos, especialmente lipopolisacáridos. Frente a estas infecciones, el huésped suele desarrollar una respuesta inflamatoria crónica. Cada vez se observa con mayor frecuencia una estrecha relación entre las infecciones bucodentales (incluida la periodontitis) y las enfermedades cardiovasculares. Varios estudios muestran que si se controlan los factores de riesgo como la edad, el sexo, las altas concentraciones de colesterol, el peso, la hipertensión y otros, las personas con enfermedad periodontal corren mayor riesgo de enfermedad cardiovascular que el resto de la población.

Chlamydia pneumoniae y otros organismos patógenos de la placa dental bucal que producen lipopolisacáridos pueden por vía de la circulación infectar los tejidos cardiovasculares y contribuir al desarrollo de aterosclerosis y al riesgo de isquemia e infarto del miocardio. En la placa dental de más de $60 \%$ de los adultos se encuentran también Streptococcus sanguis y $P$. gingivalis, que contienen una proteína asociada con la acumulación de plaquetas (PAAP), la cual, se sospecha, podría llevar al infarto del miocardio. Por otra parte, las infecciones bucodentales crónicas como la periodontitis parecen estar asociadas con las enfermedades sistémicas. Por ejemplo, la interacción con la diabetes mellitus es bien conocida. También se está investigando la relación que pueda tener la presencia de Helicobacter pylori en la cavidad bucal con la enfermedad gástrica, y la enfermedad periodontal con el enfisema pulmonar y otras enfermedades del aparato respiratorio. Dado el creciente interés por la periodontitis, se han aprobado tres nuevos tratamientos para combatirla. Además, han recibido apoyo muchos estudios básicos y de interés clínico sobre la relación planteada. Será necesario llevar a cabo estudios sobre intervenciones clínicas para determinar si la disminución de infecciones de la cavidad bucal reduce las enfermedades sistémicas. (Slavkin HC. Does the mouth put the heart at risk? JADA 130:109-113.)

\section{Un paso más hacia la eliminación de la lepra}

La lepra, una de las enfermedades más temidas a través de los siglos, está próxima a desaparecer del mundo como problema de salud pública. Sin embargo, a fines del año 2000, todavía habrá cerca de 10 países donde la carga de esa enfermedad excederá el límite de un caso por 10000 habitantes, que tiene como objetivo la Organización Mundial de la Salud. Desde 1985, el tratamiento con múltiples medicamentos ha reducido $85 \%$ de la prevalencia mundial de la lepra y el número de países con más de un caso por 10000 se ha reducido de 122 a solo 28. Mientras que en 1985 había más de 5 millones de pacientes de lepra registrados para tratamiento en todo el mundo, actualmente quedan 800 000. En 1995, la OMS empezó a distribuir los tres medicamentos indicados en paquetes nuevos de burbujas muy resistentes a la intemperie a más de 4 millones de pacientes que residen en 71 países donde la lepra es endémica. De 2 a 3 millones de personas se han salvado así de la discapacidad irreversible que puede causar la lepra no tratada.

A pesar de esos triunfos, la OMS y sus asociados en la lucha antileprosa no piensan dormirse en los laureles. En abril de 1999 el Grupo Asesor sobre la Eliminación de la Lepra se reunió en la sede de la OMS para considerar nuevas formas de hacer llegar el tratamiento a los pacientes dondequiera que vivan y conseguir que el número de casos de la enfermedad siga disminuyendo en todos los países. Con objeto de lograr su objetivo más rápidamente, el Grupo redactó una estrategia enfocada en dos propósitos: 1) examinar inmediatamente la situación de cada uno de los países que no han logrado reducir la lepra a un caso por 10000 habitantes, para determinar qué recursos les hacen falta para cumplir con ese objetivo en el año 2000 o lo más pronto posible; y 2) en los países que han logrado ese objetivo, garantizar que se mantenga el terreno ganado a nivel nacional y trabajar hacia un límite de menos de un caso por 10000 en los distritos o provincias. Uno de los problemas principales es que la lepra suele estar confinada a zonas endémicas de difícil acceso o donde por otros motivos se hace difícil llegar a los pacientes. Además es bastante común que en esos lugares haya retrasos de índole burocrática en la distribución de los medicamentos y falta de personal suficiente para diagnosticar y tratar los casos.

La OMS estima que todavía quedan casi dos millones de enfermos por detectar en los próximos 2 o 3 años y que $90 \%$ de ellos viven en 13 países de África, las Américas y Asia. En esos países las tasas de prevalencia eran de 4,4 por 10000 a principios de 1999. En la reunión del Grupo Asesor se hizo hincapié en fortalecer los vínculos con organizaciones no gubernamentales y otras entidades y en forjar nuevas alianzas. Los miembros individuales de la Federación Internacional de Asociaciones contra la Lepra y la Fundación Nippon del Japón han sido por largo tiempo aliados de la OMS en el esfuerzo por derrotar esta enfermedad. Los fondos donados por la Fundación Nippon durante 5 años han permitido hacer llegar gratuitamente a los pacientes los medicamentos para el tratamiento de la lepra. (Organización Mundial de la Salud. Leprosy elimination moves a step nearer. Comunicado de prensa, 19 de abril de 1999.) 